\title{
Role of Ball Milling of Aluminum Powders in Promotion of Aluminum-Water Reaction to Generate Hydrogen
}

\begin{abstract}
S.S. RAZAVI-TOUSI and J.A. SZPUNAR
Effect of ball milling (BM) of an aluminum powder on hydrogen generation through a reaction with hot water was investigated. BM increased surface area of the aluminum particles, increased crystalline imperfections in the aluminum lattice, and removed a native oxide film on surface of the particles. The increase in surface area of the particles was studied by measurement of particle size and examination of cross section of the particles. The effect of crystalline imperfections was studied by room temperature recovery and high temperature annealing of the ball-milled particles. The effect of the native oxide film and its thickness was studied by exposing ball-milled aluminum particles to air for different durations. Hydrogen production capability of different aluminum powders after each of the above mentioned treatments was tested and correlated to microstructural changes.
\end{abstract}

DOI: $10.1007 / \mathrm{s} 40553-014-0024-7$

(c) ASM International (ASM) and The Minerals, Metals \& Materials Society (TMS) 2014

\section{INTRODUCTION}

Aluminum (Al) can serve as a water splitting agent for the production of hydrogen. The gravimetric hydrogen capacity for the reaction of $\mathrm{Al}$ with water is $3.7 \mathrm{wt}$ pct, and the volumetric hydrogen capacity is $46 \mathrm{~g}$ $\mathrm{H}_{2} / \mathrm{L}$. Despite a high affinity of $\mathrm{Al}$ to react with water, $\mathrm{Al}$ is intrinsically resistant to corrosion in neutral $\mathrm{pHs}$. Upon exposure to air or water, a protective oxide/ hydroxide layer forms on the Al surface. This layer protects $\mathrm{Al}$ against further oxidation in contact with air or water. The reaction of an Al particle and water at a neutral $\mathrm{pH}$ forms a core-shell structure. ${ }^{[1]}$ The core is $\mathrm{Al}$ and the shell is the hydroxide phase formed around $\mathrm{Al} .{ }^{[2]}$ The ion species or/and water ${ }^{[3]}$ diffuse through the hydroxide layer and reach the $\mathrm{Al}$ core. The reaction occurs at the interface of $\mathrm{Al}$ core and the hydroxide shell. At a neutral $\mathrm{pH}, \mathrm{Al}$ containing ions diffuse outward and reach the surface of the shell. Because the solubility of $\mathrm{Al}$ ions in water is negligible, $\mathrm{Al}(\mathrm{OH})_{3}$ or $\mathrm{AlOOH}$ deposit on the surface of the shell and add to its thickness. Diffusion of ion species or/and water is considered the rate limiting step for the reaction. ${ }^{[4,5]}$ As the hydroxide layer thickens and densifies, the diffusion of ion species or/and water becomes slow and consequently, the hydrogen generation rate diminishes. ${ }^{[6]}$

Scientists have accomplished extensive research to promote the reaction of $\mathrm{Al}$ with water for hydrogen generation. Ball milling (BM) of monolithic Al powders $^{[2,7-9]}$ or Al powders with low melting point (LMP) metals such as $\mathrm{Ga}$, In, $\mathrm{Bi}, \mathrm{Hg}$, and $\mathrm{Zn},{ }^{[10-17]}$ water soluble salts such as $\mathrm{NaCl}$ and $\mathrm{KCl}^{[12,13,18-22]}$ and

S.S. RAZAVI-TOUSI, Graduate Student, and J.A. SZPUNAR, Professor, are with the Department of Mechanical Engineering, University of Saskatchewan, Saskatoon, SK S7N 5A9, Canada. Contact e-mail: ser105@mail.usask.ca, s.razavitousi@gmail.com

Manuscript submitted January 25, 2014.

Article published online July 23, 2014 ceramic powders such as $\mathrm{Al}_{2} \mathrm{O}_{3}(\alpha), \mathrm{Al}_{2} \mathrm{O}_{3}(\gamma), \mathrm{TiO}_{2}, \mathrm{C}$, $\mathrm{SiO}_{2}$, and $\mathrm{Al}(\mathrm{OH})_{3}{ }^{[22-30]}$ have been considered to activate $\mathrm{Al}$ reaction with water.

Each type of the second phase particles can promote the reaction of $\mathrm{Al}$ with water in distinctive ways. The presence of LMP metals can promote the reaction by different mechanisms: destruction of $\mathrm{Al}$ intercrystalline contacts, ${ }^{[14,31]}$ diffusion of $\mathrm{Al}$ nanoparticles through LMP metals to the reaction sites, ${ }^{[32]}$ formation of microgalvanic cells, ${ }^{[1-13,15]}$ destruction of the native alumina film, and diffusion of Al through a LMP metal layer to reach water, ${ }^{[14,15,33-35]}$ and also shifting the operating potential of $\mathrm{Al}$ to more negative values. ${ }^{[33]}$ In the case of ceramic particles, Deng et al. ${ }^{[24,25]}$ explained that a dispersion of oxide particles in the $\mathrm{Al}$ matrix can modify the protective layer and make it less strong. Dupiano et al. ${ }^{[23]}$ claimed that the dispersions of a ceramic phase can introduce new diffusion paths for $\mathrm{OH}^{-}$ions. The presence of water soluble salt particles in the Al matrix promotes the reaction by increasing the specific surface area of $\mathrm{Al}$ particles. Water dissolves the salt particles in the $\mathrm{Al}$ matrix, and thus fresh surfaces of $\mathrm{Al}$ are introduced for the reaction. ${ }^{[20,36]}$ Moreover, dissolution of the salts introduces $\mathrm{Cl}^{-}$ions, which can diffuse into the hydroxide layer and induce a localized dissolution of $\mathrm{Al}$ at the metal/oxide interface. ${ }^{[12,18,37,38]}$

Most of the above mentioned works have explained the mechanism and progress of the reaction focusing on the role of the second phase particles. In spite of variety of the works on activation of $\mathrm{Al}$ through $\mathrm{BM}$ with the second phase particles, the role of $\mathrm{BM}$ in modification of the reaction has remained obscure. Regardless of the role of $\mathrm{BM}$ in embedding the second phase particles in the $\mathrm{Al}$ matrix, $\mathrm{BM}$ can contribute to the activation of $\mathrm{Al}$ particles in three ways. First of all, BM increases the specific surface area of an $\mathrm{Al}$ powder by decreasing its particle size or/and introducing cracks and interlayer spaces inside the Al structure. ${ }^{[2]}$ Second, BM, as a severe plastic deformation method, increases lattice imperfections (grain 
boundaries, dislocations, etc.), which consequently increases affinity of the milled powder for the reaction. ${ }^{[39]}$ Third, BM breaks the native oxide film on the surface of the particles and exposes fresh surfaces for the reaction. ${ }^{[9,40]}$ Although the effects of $\mathrm{BM}$ on activation of $\mathrm{Al}$ powders are generally known, it is not clear how and to what extent each of the BM activation mechanisms can contribute to the modification of Al-water reaction.

The present work attempts to elucidate the reaction mechanism and to analyze different functions of BM in modification of Al-water reaction. We set the temperature of the reaction at $353 \mathrm{~K}\left(80{ }^{\circ} \mathrm{C}\right)$ because this is the optimum temperature for operating proton exchange membrane (PEM) and many other types of fuel cells. In order to purely study the effects of BM and the reaction mechanism of Al with hot water, we did not add any second phase powder to promote the kinetics of the reaction. Therefore, the hydrogen generation rate is low in the absence of any promoting additive, but this test directly shows how kinetics of the reaction depends on microstructure of the Al particles.

\section{EXPERIMENTAL}

\section{A. Ball Milling}

The detail of BM procedure is similar to Reference 2. Alfa Aeasar Company provided Al powder of 99.8 pct purity (MFCD00134029). The average particle size of the Al powder was $190 \mu \mathrm{m}$. We used Stearic acid (97 pct purity, Fisher Scientific-AC17449-0010) as process control agent (PCA) and mixed $3 \mathrm{wt}$ pet of it with the $\mathrm{Al}$ powder prior to milling. The role of PCA was to prevent excessive cold welding and agglomeration of the particles at the beginning of milling. A planetary ball mill (Torrey Hills- ND2L) with stainless steel cups $(285 \mathrm{~mL}$ capacity) and balls (28 of $16 \mathrm{~mm}$ and 6 of $18 \mathrm{~mm}$ diameter) milled the powders in an argon (Ar) atmosphere. Ball to powder ratio was 30:1, and the mill speed was maintained at 200 RPM for durations of $0.25,0.5$, $1,2,4,7,11$, and 19 hours.

\section{B. Particles Size Measurements}

A Laser Particle Size Analyzer (Mastersizer Particle Size Analyzer, Malvern Instruments Ltd.) measured the particle size distribution of the powders. Samples were deagglomerated in 99.9 pct ethyl alcohol prior to the measurements and their $\mathrm{D}_{50}$ is presented as the median particle size.

\section{Aging and Annealing Process}

In order to study effects of the native oxide film and room temperature aging on hydrogen production of the milled powders, we exposed a portion of the milled powder to air and stored the rest of the powder in an $\mathrm{Ar}$ atmosphere. During hydrogen measurement tests, we added the powders that were kept in Ar to water in an inert atmosphere. Therefore, considering the Ar atmosphere of the BM process, these powders did not form an oxide film prior to the reaction with water.
In order to study effect of lattice imperfections of the milled Al powders on hydrogen production rate, we used a tube furnace with an Ar atmosphere to anneal the milled Al powders. The heating rate of the furnace was $10{ }^{\circ} \mathrm{C} / \mathrm{min}$, and the annealing temperature was $823 \mathrm{~K} \pm 275 \mathrm{~K} \quad\left(550{ }^{\circ} \mathrm{C} \pm 2{ }^{\circ} \mathrm{C}\right)$. We annealed the powders for 1, 40, and 360 minutes and turned off the furnace till it reached to the room temperature, then we took the samples out of the Ar atmosphere. Considering the Ar atmosphere in the furnace, the annealing process did not change the oxide layer, but just increased grain size and released lattice strain of the samples.

\section{X-ray Analyses}

A Bruker D8 Discover X-ray diffractometer with a copper target characterized microstructure of the powders. We treated the diffraction patterns with the Rietveld refinement method, using the MAUD program, to calculate crystallite size and micro-strain of the powders. The as-received Al powder annealed for 3 hours at $823 \mathrm{~K}\left(550{ }^{\circ} \mathrm{C}\right)$ was used as the standard sample to evaluate instrumental parameters. To estimate the quality of fittings, we evaluated the refinement of each pattern using the weighted pattern factor $\left(R_{\mathrm{wp}}\right)$, the expected pattern factor $\left(R_{\text {exp }}\right)$, and the goodness of fit $(\mathrm{GoF})$ values $^{[41]}$ :

$$
\begin{gathered}
R_{\mathrm{wp}}=\left(\frac{\sum w_{i}\left(I_{\mathrm{io}}-I_{\mathrm{ic}}\right)^{2}}{\sum w_{i} I_{\mathrm{io}}^{2}}\right)^{1 / 2}, \\
G o F=\frac{R_{\mathrm{wp}}}{R_{\mathrm{exp}}} \\
R_{\exp }=\left(\frac{N-p}{\sum w_{i} I_{\mathrm{io}}^{2}}\right),
\end{gathered}
$$

where $I_{\mathrm{iO}}$ and $I_{\mathrm{iC}}$ are the observed and calculated intensities at the $i$ th step, $w_{i}=\left(1 / I_{\mathrm{iO}}\right)$ is the weight factor, $N$ is the number of observations, and $P$ is the number of adjusted parameters. We obtained acceptable fittings with $R_{\mathrm{wp}}<15$ pct and GoF $<2$ for all the Rietveld refinements.

\section{E. Hydrogen Measurement}

The detail hydrogen measurement procedure is similar to Reference 2. We added $2 \mathrm{~g} \mathrm{Al}$ powder into an Erlenmeyer flask contained $200 \mathrm{~mL}$ distilled water at temperature of $353 \mathrm{~K} \pm 276 \mathrm{~K}\left(80{ }^{\circ} \mathrm{C} \pm 3{ }^{\circ} \mathrm{C}\right)$ with a constant stirring rate of $120 \mathrm{rpm}$. The produced hydrogen gas passed through a desiccant $\left(\mathrm{CoCl}_{2}\right)$ to absorb moisture, and then an ADM2000 flowmeter measured its flow with an accuracy of $0.1 \mathrm{~mL} / \mathrm{min}$. The flowmeter was connected to the computer, and ADM Trend software acquired the data. We measured the flow for the first 1 to 2 hours of the reaction for each sample and then normalized the results for 1 gr Al powder. We did not continue measuring hydrogen flow after 2 hours of the reaction because the collected data were sufficient to 
investigate effect of microstructure on the rate of Alwater reaction.

We obtained a baseline curve by measuring the flow from $200 \mathrm{~mL}$ distilled water at temperature of $353 \mathrm{~K}$ $\left(80{ }^{\circ} \mathrm{C}\right)$ with a constant stirring rate of $120 \mathrm{rpm}$ with no Al powder added. The baseline data were subtracted from the data obtained from the reactions to ensure that the measurements did not include water moisture or expansion of air in the flask during heating.

\section{F. Scanning Electron Microscopy}

A Hitachi SU6600 field emission scanning electron microscope (SEM) examined cross section of the powders after BM. We added a small amount of the powder to a conductive carbon resin powder, mixed and mounted it. We polished the mounted samples by abrasive grinding papers from 600 to 1600 grit followed by additional grinding with diamond pastes. Finally, to get high quality surfaces, the samples were polished using a Hitachi IM4000 Ar ion milling system. A Nordlys Nano Oxford detector collected electron backscattered diffraction (EBSD) patterns at a voltage of $20 \mathrm{kV}$ with a tilt degree of $70 \mathrm{deg}$.

\section{G. X-ray Photoelectron Spectroscopy (XPS)}

An AXIS 165 spectrometer (Kratos Analytical) performed XPS tests with a monochromatic Al $\mathrm{K}_{\alpha}$ source $(h v=1486.6 \mathrm{eV})$ used at a power of $140 \mathrm{~W}$. The base pressure in the analytical chamber was lower than $5 \times 10^{-8} \mathrm{~Pa}$. The analysis spot was $400 \times 700 \mu \mathrm{m}$, and the take-off angle was $90 \mathrm{deg}$. The survey scans were collected for binding energy spanning from $1100 \mathrm{eV}$ to 0 with analyzer pass energy (PE) of $160 \mathrm{eV}$ and a step of $0.4 \mathrm{eV}$, and high-resolution spectra with $\mathrm{PE}=20 \mathrm{eV}$ and step of $0.1 \mathrm{eV}$. Charge compensation was not required. Aluminum oxide thickness was evaluated using the method suggested by Strohmeier. ${ }^{[42]}$ Instrument software Vision2 performed the component analysis of high-resolution spectra of $\mathrm{Al} 2 \mathrm{p}$ and calculation of the areas of oxide and metallic peaks.

\section{RESULTS AND DISCUSSION}

\section{A. Ball Milling Effect: Morphological Changes}

Figure 1 shows effect of milling time on particle size of the Al powder. One observes that BM up to 1 hour increases the particle size. More BM after 1 up to 4 hours sharply decreases the particle size, while further milling after 4 hours does not significantly change it. The initial increase in the particle size is attributed to cold welding of the ductile Al particles that result from the balls impacts. One the other hand, the balls impacts deform ductile particles during BM, which consequently increase the hardness of the particles because of work hardening. ${ }^{[40]}$ The work-hardened Al particles fracture to smaller ones as BM continues resulting in the decrease in the particle size after 1 hour of milling. During 4 to 19 hours of BM, two mechanisms of cold welding and fracturing of the particles reach some equilibrium; therefore, BM results in no remarkable change of the particle size. Previous studies have established the effect of BM time on the particle size of a ductile powder and the trend observed in Figure 1 is typical. ${ }^{[43-45]}$

Figure 2 shows the cross section of an as-received Al particle and Al particles milled for 1, 4, 7, 11, and 19 hours. Apart from changes in shape and size of the particles resulted from $\mathrm{BM}$, one can notice that the 7 and 4 hours milled particles have a laminated structure. Cold welding of flattened $\mathrm{Al}$ particles produces this laminated structure. ${ }^{[43]}$ The presence of interlayer spaces between the layers of the 4 and 7 hours milled particles increases their specific surface area.

Figure 3 shows hydrogen flow $v s$ time for the reaction of water with the Al powders milled for different times. We did not observe hydrogen generation for the asreceived $\mathrm{Al}$ powder and also the powders milled for 0.25 , 0.5 , and 1 hour, for that reason they are not reported in Figure 3. In other words, we did not observe formation of bubbles, and no flow was measured by the flowmeter. The zero hydrogen generation of some aluminum powders in reaction with water during the first hour up to 80 hours of immersion has been observed in different works. ${ }^{[1,20,24,46]}$

This zero hydrogen generation can be explained in two ways; the reaction did not start, or, the reaction started, but it was very slow so that no hydrogen flow was measured (the accuracy of the flowmeter for our experiments was $0.1 \mathrm{~mL} / \mathrm{min}$ ). Even the 1 hour milled particles, which most probably their oxide film was removed during milling, did not produce any measurable hydrogen. Thermodynamically, the reaction occurs, when the oxide film is removed. Therefore, it can be concluded that the zero hydrogen production of the asreceived particles and the powders milled for 15 , 30 minutes, and 1 hour can be explained by a very slow reaction rate because of the limited specific surface area and rather low affinity for the reaction.

One can see that the hydrogen flow increases as milling time increases up to 7 hours, but after 7 hours

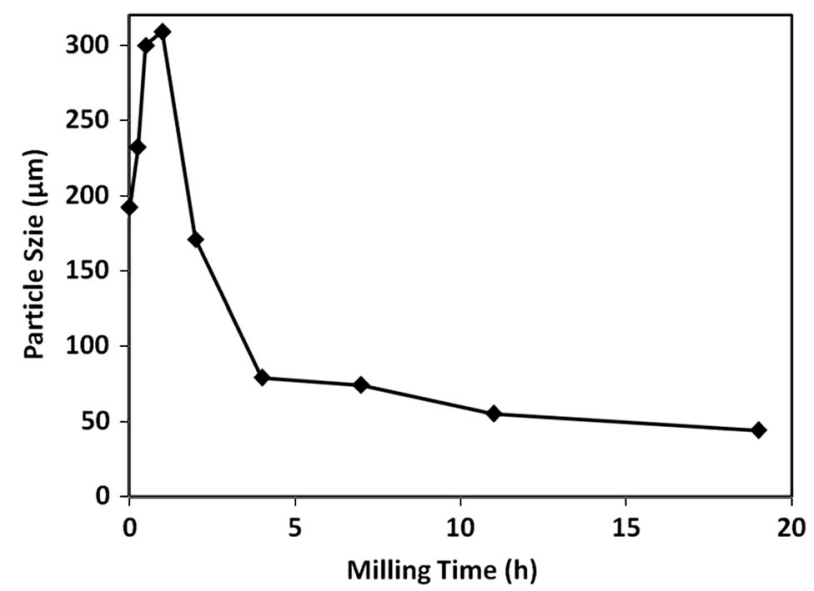

Fig. 1-Effect of milling time on average particle size $\left(D_{50}\right)$ of the $\mathrm{Al}$ powder. 

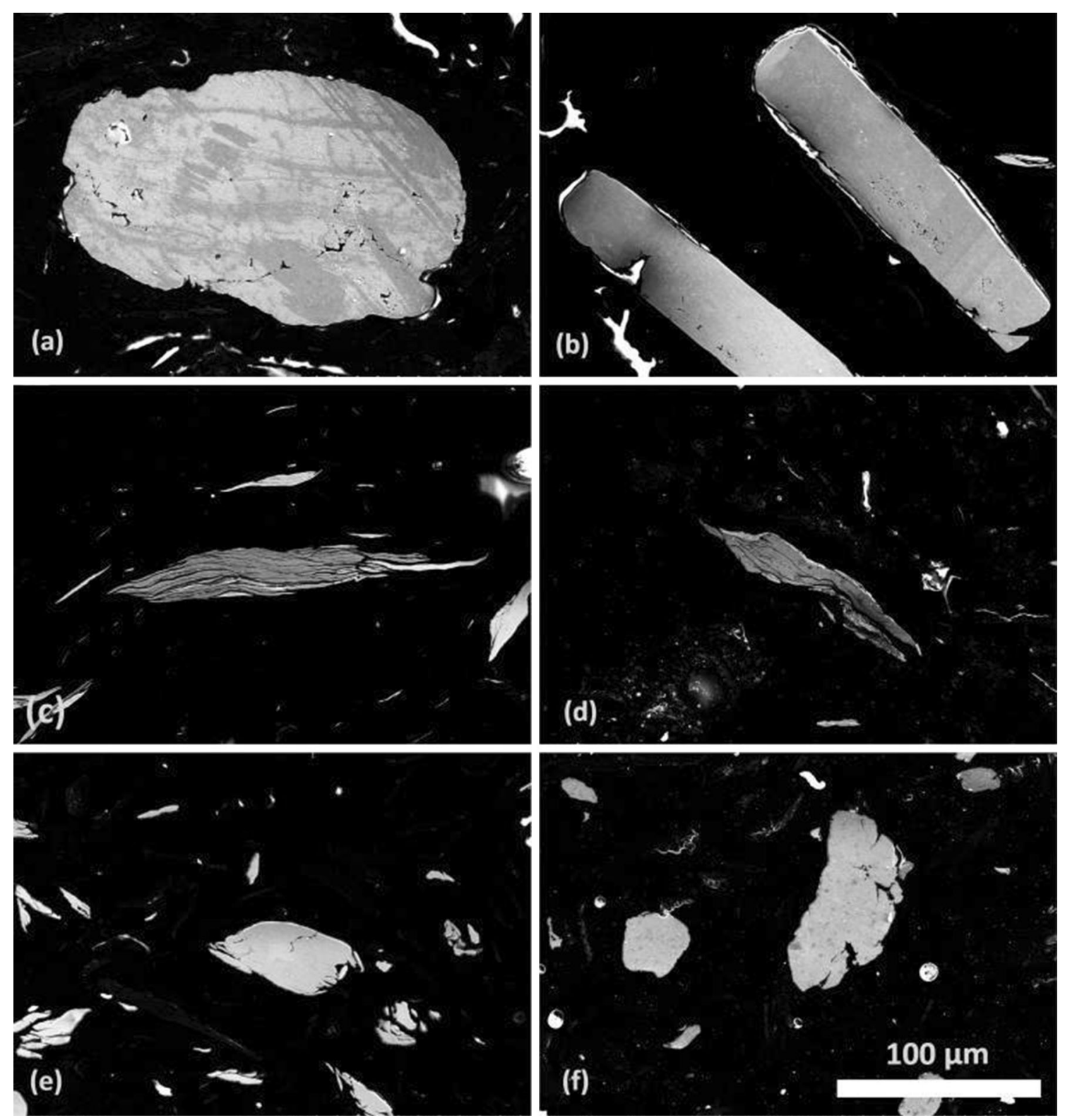

Fig. 2-SEM images of cross section of $(a)$ the as-received Al particle and the Al particles milled for $(b) 1 \mathrm{~h},(c) 4 \mathrm{~h},(d) 7 \mathrm{~h},(e) 11 \mathrm{~h}$, and $(f)$ 19 h.

milling, it decreases. The higher hydrogen production rate of 4 and 7 hours milled samples is because of the presence of internal surfaces due to the laminated structure of these samples. Further milling up to 11 or 19 hours eliminated the internal surfaces. Therefore, the reaction happens just on the outer surface of 11 and 19 hours milled samples and hydrogen production rate decreases.

Considering Figures 1 through 3 , one realizes that $\mathrm{BM}$ increases the specific surface area of the $\mathrm{Al}$ powders in two ways: first by reducing the particle size, second by generating interlayer spaces inside the particles. Since the reaction of $\mathrm{Al}$ and water initiates on and continues through the surfaces (either on or in particles), BM improves kinetics of the reaction by providing more $\mathrm{Al}$ sites reachable for water.
Several studies have reported that BM improves reaction of $\mathrm{Al}$ powders with water by modifying the size or specific surface area of Al particles. $^{[2,7,10,13,18-20,22,28,29,47]}$ Among the mentioned studies, some reported that although $\mathrm{BM}$ activates $\mathrm{Al}$ powders, extended milling after a particular time can decrease the hydrogen yield. ${ }^{[2,10,13,22,28,29,47-49]}$ The twofold effect of BM time remained unexplained in most of the mentioned studies. Some researchers ascribed this effect to oxidation of $\mathrm{Al}$ particles during BM. ${ }^{[10,22,28]}$ However, they did not perform crosssectional examination of the $\mathrm{Al}$ particles to investigate the role of internal surfaces on the reaction rate. In the present work, we performed milling in an $\mathrm{Ar}$ atmosphere, thus, no oxidation happened during milling. In the absence of oxidation, Figures 1 through 


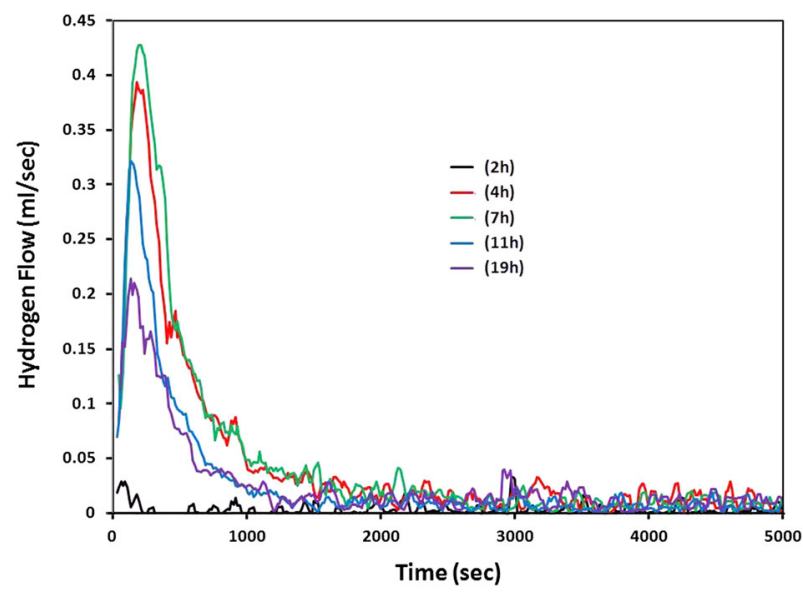

Fig. 3-Hydrogen generation flow vs time for the reaction of water with the Al powders milled for different durations.
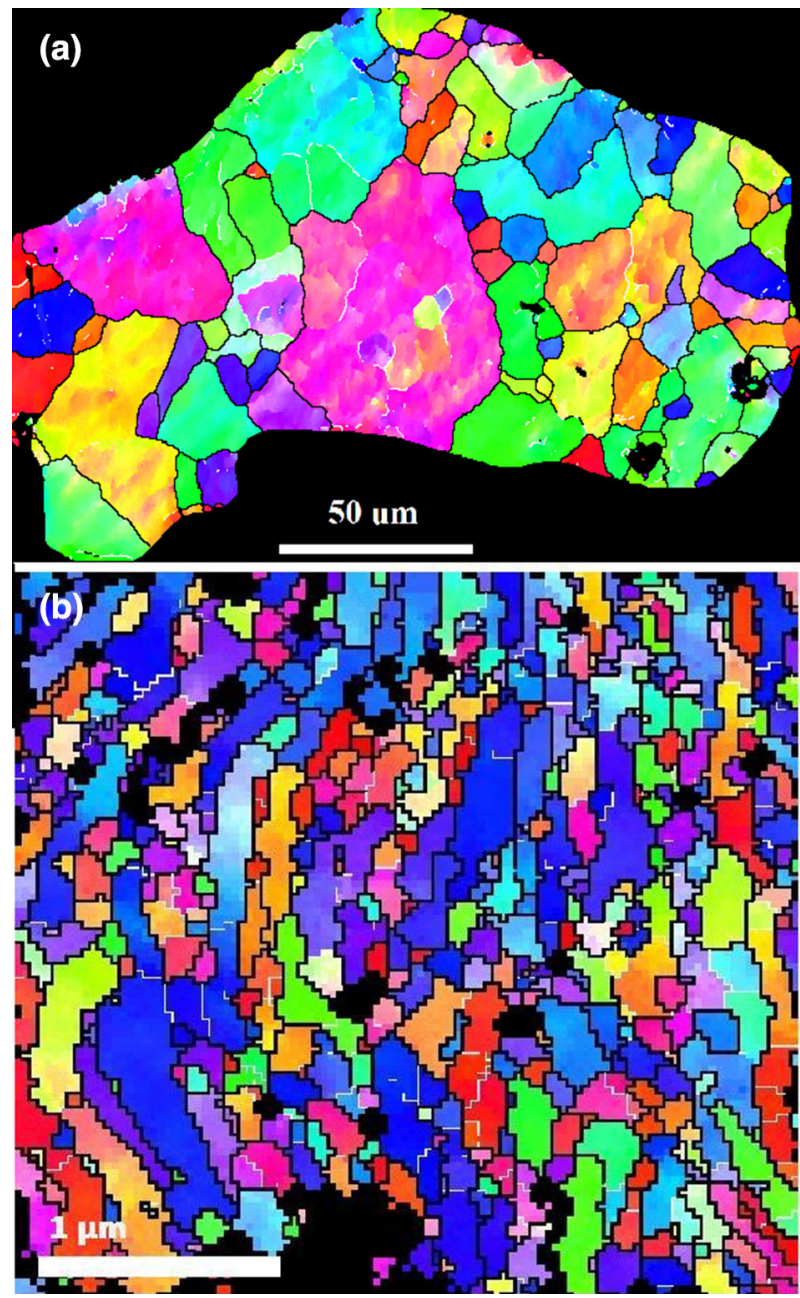

Fig. 4-EBSD patterns of the as-received $\mathrm{Al}$ particle (step size: $0.65 \mu \mathrm{m})$ and the Al particle milled for $11 \mathrm{~h}$ (step size: $0.03 \mu \mathrm{m})$, note the difference in the scale bars.

3 allows to establish that a prolonged $\mathrm{BM}$ can reduce the hydrogen generation rate by eliminating internal surfaces inside Al particles produced during early stages of milling.

\section{B. Ball Milling Effect: Lattice Imperfection Changes}

In spite of the numerous works on $\mathrm{BM}$ of $\mathrm{Al}$ for the reaction with water, not enough attention has been paid to the role of $\mathrm{BM}$ in introducing lattice defects to the $\mathrm{Al}$ lattice and consequently, its effect on hydrogen production rate. BM, as a severe plastic deformation technique, introduces lattice imperfections like grain boundaries and dislocations to microstructure of milled particles. Figure 4 shows EBSD patterns of an as-received Al particle and an Al particle milled for 11 hours. Different colors represent different orientations, and the white and black lines represent grain boundaries with misorientation of 5 to $15 \mathrm{deg}$ and over $15 \mathrm{deg}$, respectively. The average grain size (misorientation cut-off: $15 \mathrm{deg}$ ) of the Al particles was $32 \mu \mathrm{m}$ before milling which changed to $0.33 \mu \mathrm{m}$ after 11 hours milling. The proportion of atoms that lie at intercrystalline regions as a total of surface area becomes significant as the grain size decreases. A decrease of 2 orders of magnitude in the grain size introduces many grain boundaries to the Al lattice.

To the knowledge of the authors, effect of Al lattice imperfections on hydrogen generation rate has not been studied so far. However, effect of Al lattice imperfections, mainly as a reaction promoting driving force, has been noted in few studies. David and Kopac, Zhao et al., and Luo et al. discussed that deformation of $\mathrm{Al}$ particles by $\mathrm{BM}$ promotes the hydrogen production rate, but they did not perform experiments to prove that. ${ }^{[7,18,19]}$ Wang et al. observed that a finer grain $\mathrm{Al}$ has a higher hydrogen generation rate. ${ }^{[32]}$ They ascribed that to the presence of a LMP metal layer on grain boundaries, which facilitates reaction of Al with water. Veddar and Vermilye ${ }^{[4,50]}$ and Hart ${ }^{[50]}$ also noticed that the reaction of $\mathrm{Al}$ and hot water mainly occurs at grain boundaries. Veddar and Vermilye ascribed the higher corrosion that occurs at grain boundaries as a result of intense removal of electrons from grain boundaries, which increases hydroxyl ion concentration and results in more rapid destruction of the protective film. They found that the hydroxyl attack on the grain boundaries is 4 times as fast as on the surface grains. ${ }^{[4]}$ Dupiano et $a .^{[23]}$ aged ball-milled Al powder for 1200 hours at $40{ }^{\circ} \mathrm{C}$ in air and found a significant decrease in hydrogen generation rate. However, no further investigation was performed to explain the aging effect. Czech and Troczynski ${ }^{[22]}$ Ball milled a mixture of $\mathrm{Al}-\mathrm{NaCl}$ powder and annealed the produced powder at $823 \mathrm{~K}\left(550{ }^{\circ} \mathrm{C}\right)$ for 1 hour. They measured hydrogen generation rate before and after annealing and found no significant difference. However, the effects of BM and annealing on the lattice imperfections have not been reported.

\section{Recovery effect}

In order to study effect of lattice imperfections on kinetics of the reaction, we treated the milled powders with room temperature aging and high temperature annealing. Figure 5 shows hydrogen generation of the 7 hours milled samples kept in an Ar atmosphere at room temperature for $2.5,8$, and 16 days. One observes a lower hydrogen generation rate for the samples aged for the longer times. Since the samples were not exposed 


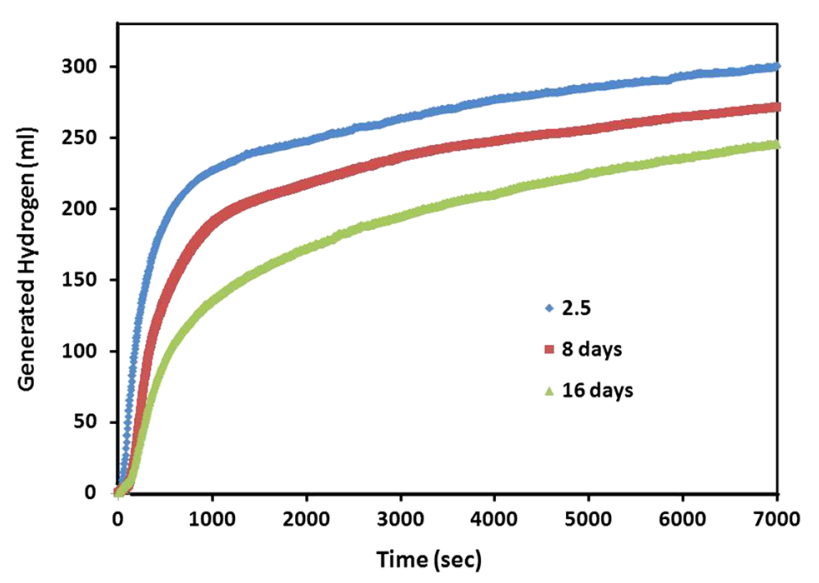

Fig. 5-Hydrogen generation of the $7 \mathrm{~h}$ milled samples aged at room temperature in $\mathrm{Ar}$ atmosphere for 2.5, 7, and 16 days.

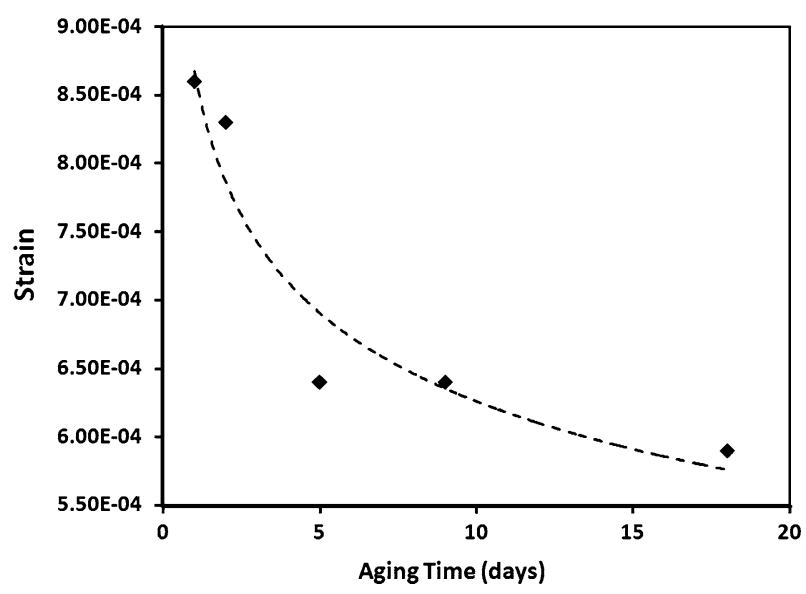

Fig. 6-Effect of aging time on micro-strain of the $7 \mathrm{~h}$ milled powder.

to oxygen prior to the reaction, the only explanation for the different reaction rates is room temperature recovery and possible grain growth.

In order to explain the effect of aging time on the reaction rate, we performed Rietveld refinement on XRD patterns of the 7 hours milled samples aged for 1, 2, 5, 9, and 18 days. We found that crystallite size of the samples did not change significantly with aging time; however, micro-strain decreased with time. Figure 6 shows changes in micro-strain of 7 hours milled powder $v s$ aging time. The micro-strain decreases by over 30 pct between 1 and 18 days of aging. Room temperature instability (recovery, recrystallization, or grain growth) is a well-known phenomenon for ultrafine grained or nanocrystalline metals. ${ }^{[51-54]}$ As the crystallite size of the 7 hours Ballmilled $\mathrm{Al}$ powders was rather stagnant ( 95 to $105 \mathrm{~nm}$ ), one can gather that just recovery and dislocation rearrangement happened during the aging time. Accordingly, the change in microstructure of the deformed $\mathrm{Al}$ particles toward a more stable state is the reason for the lower hydrogen generation rate of the aged samples.

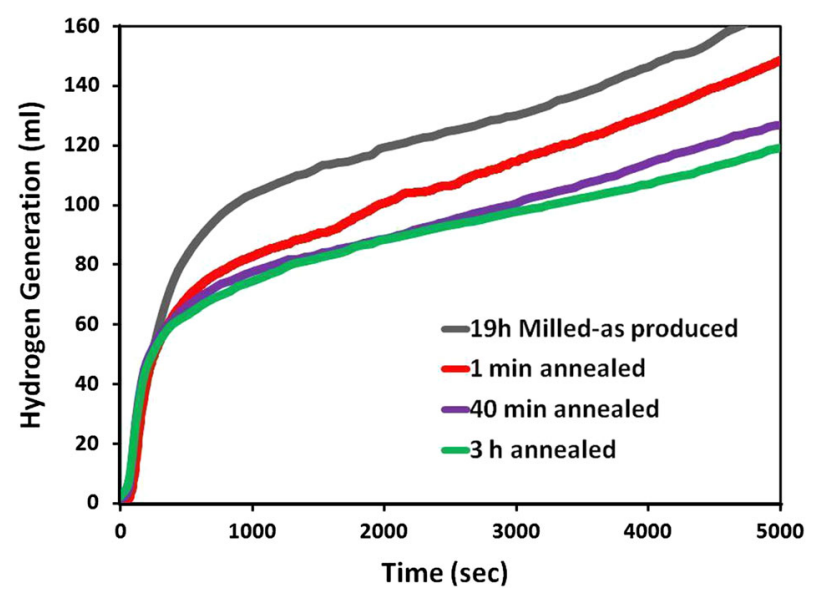

Fig. 7-Hydrogen generation of the as produced $19 \mathrm{~h}$ milled sample and the $19 \mathrm{~h}$ milled sample annealed at $823 \mathrm{~K}\left(550{ }^{\circ} \mathrm{C}\right)$ for 1,40 and 180 min at Ar atmosphere.

\section{Annealing effect}

Figure 7 shows hydrogen generation of the 19 hours milled sample and the 19 hours milled samples annealed at $823 \mathrm{~K}\left(550{ }^{\circ} \mathrm{C}\right)$ for 1,40 , and 180 minutes at an $\mathrm{Ar}$ atmosphere. One observes that annealing for 1 or 40 minutes results in remarkable changes in hydrogen generation rate; however, further annealing after 40 up to 180 minutes does not significantly affect the reaction rate. The results of Rietveld refinement of XRD of the annealed samples are shown in Figures 8(a) and (b). The crystallite size increased and micro-strain in the samples decreased with annealing time.

Thermodynamically, the presence of a high amount of grain boundaries increases microstructural instability and thus, fine grains in deformed metals have a higher affinity for reactions than coarse grains in recrystallized metals. However, a higher affinity of the fine grain metals for reactions does not necessarily lead to a higher corrosion rate. An obvious contradiction exists among results of different works reporting effect of grain size/ residual stress on corrosion resistance of different metals. ${ }^{[5]}$ The disagreement has been reported for corrosion resistance of different alloys of the same metal. For example, in the case of Al alloys, it was reported that grain size reduction and deformation result in a better corrosion resistance ${ }^{\left[{ }^{[5-60]}\right.}$ while other papers results show the opposite. ${ }^{[61-63]}$ One can, however, explain the existing contradiction assuming different corrosion mechanisms. For example, a decrease in grain size results in an increase in corrosion rate of a metal with primary intergranular corrosion mechanism, while an opposite effect would be expected for a metal with a pitting corrosion mechanism. Ralston et al..$^{[64]}$ discussed that a finer grain size increases corrosion resistance of a metal that forms a protective layer. The finer grain size increases reactivity and thus, a uniform protective film forms faster and protects the metal from further corrosion. On the other hand, the deformed state of a metal can make it more susceptible to corrosion if protective film on the metal is not formed. 


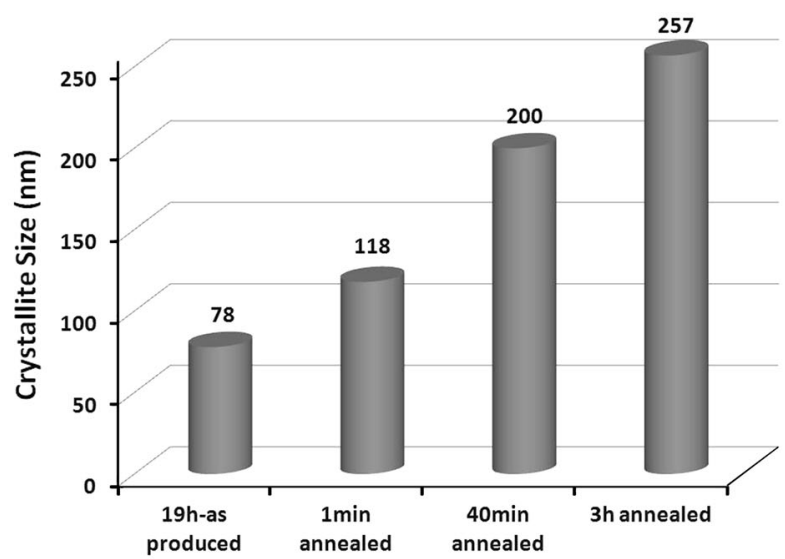

(a)

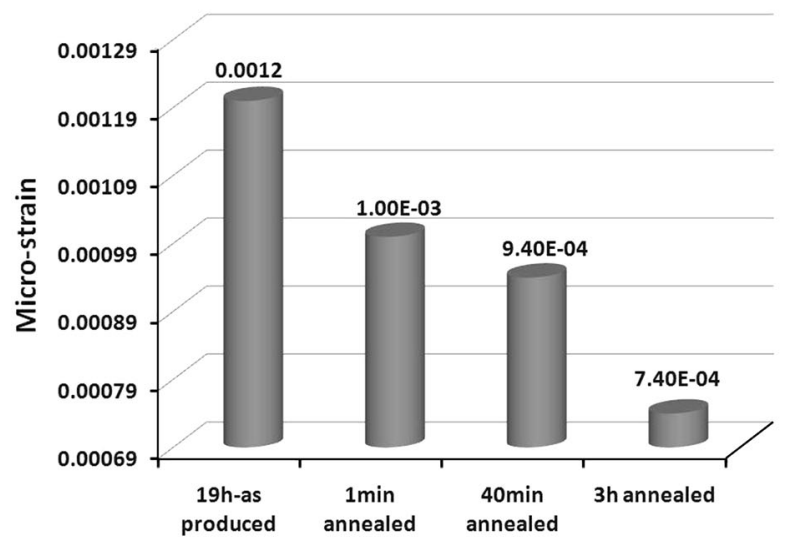

(b)

Fig. 8-Effect of duration of the annealing process at $823 \mathrm{~K}$ $\left(550^{\circ} \mathrm{C}\right)$ on $(a)$ crystallite size and $(b)$ micro-strain of the $19 \mathrm{~h}$ milled powder.

The protective nature of the oxide film on Al surface varies in different oxidizing media and at different temperatures. Regarding the reaction of $\mathrm{Al}$ with hot water at neutral $\mathrm{pHs}$, the oxide film on the surface of $\mathrm{Al}$ gradually transforms to a hydroxide film, this film is less protective than the oxide layer. ${ }^{[3]}$ After the oxide film is hydrated, ion species can diffuse through the film and reach and oxidize the $\mathrm{Al}$ substrate. ${ }^{[65]}$ Higher temperatures increase diffusivity of the ion species, which makes the hydrated layer less protective. Considering the semiprotective nature of the hydroxide film on the surface of the $\mathrm{Al}$ immersed in hot water, a finer grain size and deformed Al substrate cannot reduce the corrosion by a fast and uniform formation of the protective layer. But the deformed state of the microstructure promotes the corrosion by increasing the affinity of water to react with the $\mathrm{Al}$ substrate. Consequently, as Figures 5 and 7 show, the rate of the reaction between the deformed $\mathrm{Al}$ particles and hot water decreases as the microstructure is stabilized by either room temperature aging or high temperature annealing. There is a negligible difference between hydrogen generation rate of 40 and 180 minutes annealed samples (Figure 7), while the difference is considerable for different crystallite size and micro-strain of the

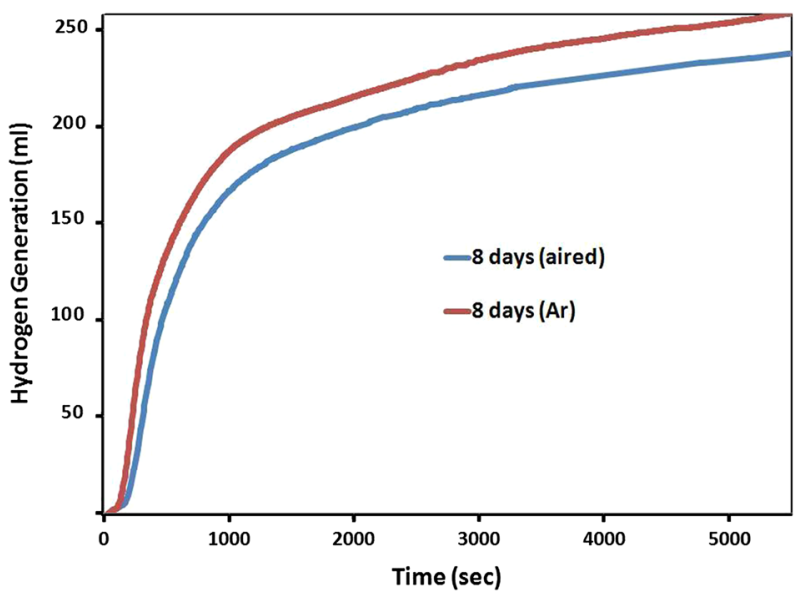

Fig. 9-Hydrogen generation of the $7 \mathrm{~h}$ milled $\mathrm{Al}$ powders kept for 8 days in Ar or air.

mentioned samples (Figures 8(a) and (b)). Hence, it is concluded that a significant change in the stored deformation energy in the Al lattice does not necessarily lead to a significant change in hydrogen production rate, but it depends on the range in which the crystallite size and micro-strain change.

\section{Ball Milling Effect: Removal of the Native Oxide Film}

Reviewing the literature on activation of $\mathrm{Al}$ by BM, one can realize that breaking and removal of the native oxide film on the surface of Al particles is the most known effect of this process. Although elimination of the native oxide film by BM is well established, one must note that this role of $\mathrm{BM}$ is effective as long as milled $\mathrm{Al}$ particles are not exposed to air before the reaction. A new native oxide film forms upon exposing the milled Al powder to air. In order to study effect of the native oxide film, we exposed part of the Ball-milled powders to air and kept part of it in an Ar atmosphere and then performed the hydrogen generation test on these powders.

Figure 9 shows hydrogen generation from the 7 hours milled Al powders kept for 8 days in Ar or air after BM. The overall shape of the aired and Ar curves is quite the same, but for the 7 hours milled Al powder kept in Ar, the reaction initiates faster than the one kept in air. The delay in starting the reaction for the air kept powder is so called "induction period" or "incubation time". There are two explanations for the presence of an incubation time before $\mathrm{Al}$ reaction with water starts. The first explanation is that the time is needed for hydration of the native Al oxide film by water. When the hydration front reaches the $\mathrm{Al}$ substrate, hydrogen generation starts. ${ }^{[3,66]}$ The second explanation is dissolution of the native oxide film in water and precipitation of the dissolved ions (in $\mathrm{pH}$ of 3 to 10) as aluminum oxide hydroxide on the surface of Al substrate. ${ }^{[5,67,68]}$ Regardless of what explanation is closer to reality, the outcome of the both is that before hydrogen generation starts, $\mathrm{Al}-\mathrm{O}$ bonds in the oxide film should be broken and replaced by Al-hydroxide bonds. The time needed for substitution of the $\mathrm{Al}-\mathrm{O}$ bonds in the film with 
Al-hydroxide bonds delays hydrogen generation of the air kept sample compared to the one kept in Ar.

One may notice that even the sample that was kept in Ar does not initiate hydrogen production instantly. We attribute the delay in hydrogen generation of the sample kept in Ar to a possible formation of oxide layer because of the presence of oxygen impurity in Ar, or a slight exposure to air during handling of the milled powders. The affinity of $\mathrm{Al}$ to react with oxygen is high in a way that the ball-milled powder can hardly be fully protected against formation of the film. In other words, a film may exist on the surface of the ball-milled powders; however, the film could not thicken similar to that of the powders that were completely exposed to air for a long time.

There are few studies that considered effect of air storage of activated Al powders on incubation time; however, their results are contradictory. Ilyukhina et $a l^{[14]}$ found that air storage of 3 minutes milled $\mathrm{Al}$ particles with LMP metals does not affect incubation time. Dupiano et al. ${ }^{[23]}$ also found no change in incubation time after $40{ }^{\circ} \mathrm{C}$ aging of a milled $\mathrm{Al}$ powder. On the other hand, Zhao et al., ${ }^{[18]}$ Streletskii et al., ${ }^{[28]}$ and Parmuzina et al..$^{[15]}$ noticed significant changes in incubation time as storage in the air was extended. Chen et $a l .{ }^{[69]}$ found that not only the incubation time is affected by the storage time, but also the hydrogen yield of the reaction decreases by longer storage periods. We tend to agree more with the result of the latter authors, because if the activation process of Al powders removed the oxide film, an exposure to air should form the film on the surface and a longer aging time should slow down the hydrogen generation. Dupiano et al. ${ }^{[23]}$ collected data points using big time intervals, and the incubation period, even if it existed, could not be identified. Ilyukhina et al. ${ }^{[14]}$ ball milled the $\mathrm{Al}$ powder for 3 minutes; such a short milling time could only partially remove the oxide film, thus, they did not observe any change in the incubation time even after 63 days of air storage.

In order to verify the effect of duration of air storage on incubation time, we kept the 7 hours milled powders in air for different durations up to 23 days and then measured their hydrogen production. Figure 10 shows hydrogen generation of the 7 hours milled Al powders kept for different times in air. The hydrogen generation rate decreases dramatically as the powder was kept for longer periods in air. This decrease can be justified by two phenomena. The first phenomenon is the effect of room temperature aging on the native oxide film on the surface of the powder particles. A change in the oxide film can be inferred from the increasing incubation time as the powder was kept longer in air. The oxide film can grow thicker as the powder is exposed longer to air. The second phenomenon can be inferred from hydrogen production rate. Even when the reaction starts after the delay due to the incubation time, the amount of hydrogen generated from the longer aged powders was smaller than that from particles aged for shorter time. As explained in Section III-B, the second phenomenon is because of a room temperature recovery of the

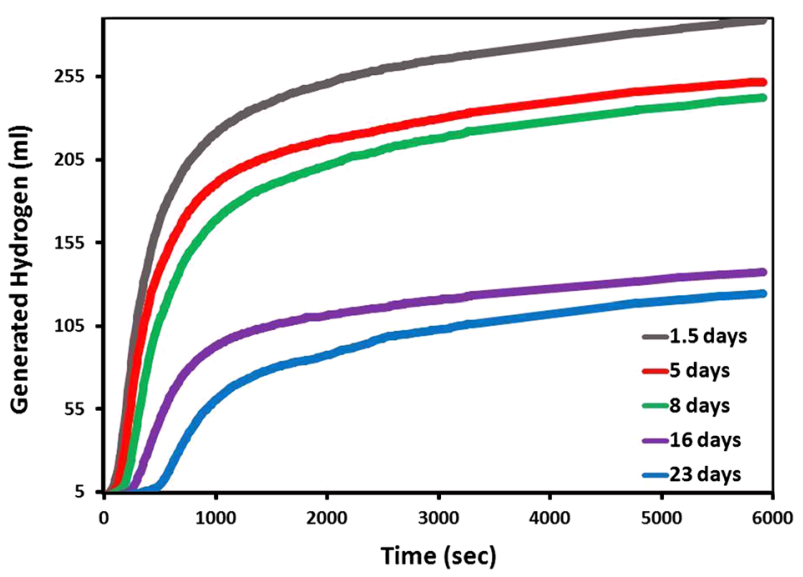

Fig. 10-Effect of duration of the room temperature aging in air on hydrogen generation of the $7 \mathrm{~h}$ milled $\mathrm{Al}$ powders.

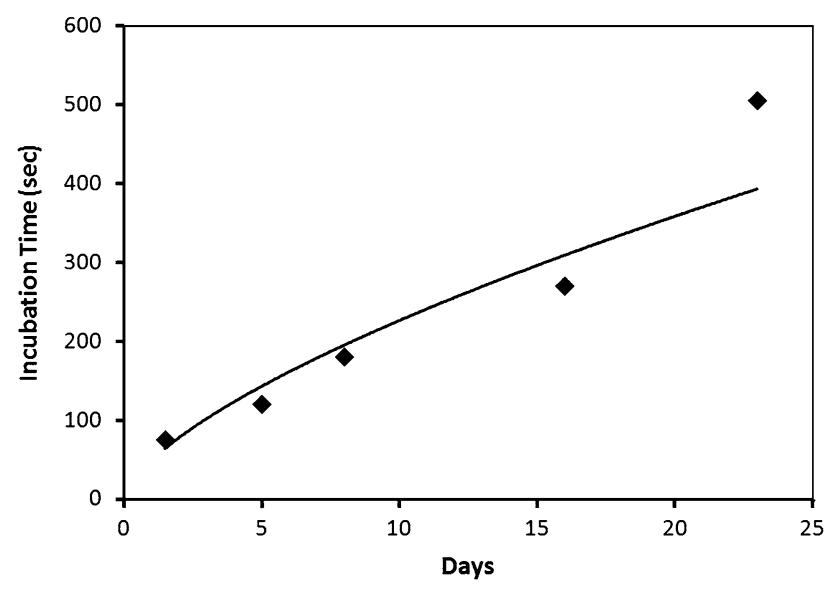

Fig. 11-Effect of aging time on the incubation time of the hydrogen generation reaction.

deformed $\mathrm{Al}$ powder, which diminishes $\mathrm{Al}$ affinity to react with water.

In order to study the effect of room temperature aging in air on the incubation time, we extracted the delay time by a linear slope fitting of the curves in Figure 10. We also measured the thickness of the oxide film on the surface of the milled powder by XPS to find a correlation between aging time, oxide thickness, and incubation time. Figure 11 shows effect of number of days of aging on the incubation time. The incubation time increases as the aging time increases. Figure 12 shows effect of aging time on the thickness of the native oxide film. The oxide film thickness also increases with the aging time. The solid line represents a power law fitting to the experimental data. A thickness of $7.4 \mathrm{~nm}$ was measured for the as-received particles, and is presented in Figure 12. One can see that even after 54 days of the exposure of the milled powder to air, the thickness of the oxide layer on the surface of the asreceived particles is bigger than that of the milled powder. Considering Figures 11 and 12, one realizes that the aging at room temperature causes an increase in 


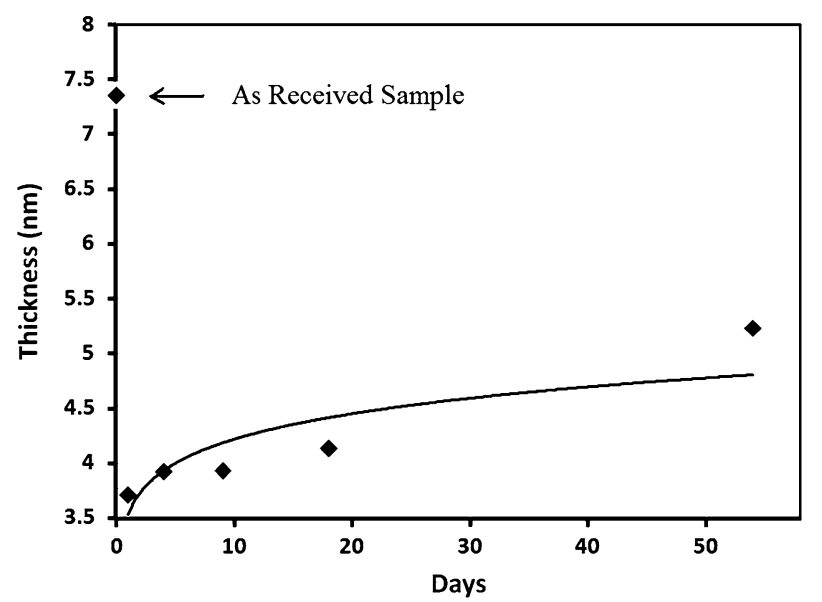

Fig. 12-Effect of aging time on thickness of the native oxide film measured by XPS.

thickness of the oxide film, and accordingly, the incubation time increases.

\section{CONCLUSIONS}

In addition to the role of $\mathrm{BM}$ in incorporating additives to aluminum powders to promote hydrogen generation during the reaction of aluminum with water, $\mathrm{BM}$ contributes in the production of hydrogen in three distinct ways:

1. BM increases surface of the particles by decreasing the particles size and introducing a laminated structure inside the particles. The role of interlayer spaces inside the particles is significant in a way that for prolonged BM times where the laminated structure is eliminated, the hydrogen generation rate considerably decreases.

2. BM introduces crystallographic imperfections into lattice of the aluminum particles, which increases affinity of the particles for the reaction. A partial annihilation of the crystallographic imperfections by either the room temperature recovery (decrease in the lattice micro-strain) or the high temperature annealing (decrease in the lattice micro-strain and increase in the crystallite size) markedly decreased the hydrogen generation rate.

3. BM removes the native oxide film formed on the surface of the aluminum particles. The absence of the protective film makes the reaction to start almost without the delay resulted from a hydration of the oxide film. However, the protective film forms on the fresh surfaces as the particles are exposed to air. The film grew in the span of our measurements ( 1 to 56 days) resulting in an increase in the incubation time of the reaction.

In spite of the common attention to the oxide removal by ball milling, the present results established that the role of BM in introducing crystallographic defects and new surfaces to the aluminum particles is more substantial for hydrogen generation. The presence of the native oxide film affects the start of the reaction, while the latter effects can substantially change the overall efficiency of hydrogen generation.

\section{ACKNOWLEDGMENTS}

We acknowledge the NSERC discovery grant and support of Canada Research Chair program. We also appreciate the contribution of ACSES centre in University of Alberta in performing XPS tests.

\section{REFERENCES}

1. H.Q. Nie, S.S. Zhang, M. Schoenitz, and E.L. Dreizin: Int. J. Hydrog. Energy, 2013, vol. 38, pp. 11222-32.

2. S.S. Razavi-Tousi and J.A. Szpunar: Int. J. Hydrog. Energy, 2013, vol. 38 , pp. $795-806$.

3. B.C. Bunker, G.C. Nelson, K.R. Zavadil, J.C. Barbour, F.D. Wall, J.P. Sullivan, C.F. Windisch, M.H. Engelhardt, and D.R. Baer: J. Phys. Chem. B, 2002, vol. 106, pp. 4705-13.

4. W. Vedder and D.A. Vermilye: Trans. Faraday Soc., 1969, vol. 65, pp. $561-64$.

5. D.A. Vermilyea and W. Vedder: Trans. Faraday Soc., 1970, vol. 66 , pp. $2644-54$.

6. S.S. Razavi-Tousi and J.A. Szpunar: Electrochim. Acta, 2014, vol. 127, pp. 95-105.

7. E. David and J. Kopac: J. Hazard. Mater., 2012, vol. 209, pp. 501-09.

8. M. Watanabe: J. Phys. Chem. Solids, 2010, vol. 71, pp. 1251-58.

9. S.S. Razavi-Tousi, G.A. Nematollahi, T. Ebadzadeh, and J.A. Szpunar: Powder Technol., 2013, vol. 241, pp. 166-73.

10. M.Q. Fan, L.X. Sun, and F. Xu: Energy Convers. Manag., 2010, vol. 51 , pp. 594-99.

11. M.Q. Fan, F. Xu, and L.X. Sun: Int. J. Hydrog. Energy, 2007, vol. 32, pp. 2809-15.

12. M.Q. Fan, F. Xu, and L.X. Sun: Energ Fuel, 2007, vol. 21, pp. 2294-98

13. M.-Q. Fan, L.-X. Sun, and F. Xu: Energy, 2010, vol. 35, pp. 1333-37.

14. A.V. Ilyukhina, O.V. Kravchenko, B.M. Bulychev, and E.I. Shkolnikov: Int. J. Hydrog. Energy, 2010, vol. 35, pp. 1905-10.

15. A.V. Parmuzina, O.V. Kravchenko, B.M. Bulychev, E.I. Shkol'nikov, and A.G. Burlakova: Russ. Chem. Bull., 2009, vol. 58, pp. 493-98.

16. H. Wang, Y. Chang, S. Dong, Z. Lei, Q. Zhu, P. Luo, and Z. Xie: Int. J. Hydrog. Energy, 2013, vol. 38, pp. 1236-43.

17. X. Chen, Z. Zhao, M. Hao, and D. Wang: Int. J. Energy Res., 2013, vol. 37, pp. 1624-34.

18. Z.W. Zhao, X.Y. Chen, and M.M. Hao: Energy, 2011, vol. 36, pp. 2782-87.

19. H. Luo, J. Liu, X.X. Pu, J. Liang, Z.J. Wang, F.J. Wang, K. Zhang, Y.J. Peng, B. Xu, J.H. Li, and X.B. Yu: J. Am. Ceram. Soc., 2011, vol. 94, pp. 3976-82.

20. B. Alinejad and K. Mahmoodi: Int. J. Hydrog. Energy, 2009, vol. 34, pp. 7934-38.

21. K. Mahmoodi and B. Alinejad: Int. J. Hydrog. Energy, 2010, vol. 35, pp. 5227-32, 5932.

22. E. Czech and T. Troczynski: Int. J. Hydrog. Energy, 2010, vol. 35, pp. 1029-37.

23. P. Dupiano, D. Stamatis, and E.L. Dreizin: Int. J. Hydrog. Energy, 2011, vol. 36, pp. 4781-91.

24. Z.Y. Deng, Y.B. Tang, L.L. Zhu, Y. Sakka, and J.H. Ye: Int. J. Hydrog. Energy, 2010, vol. 35, pp. 9561-68.

25. Z.Y. Deng, J.M.F. Ferreiraw, Y. Tanaka, and J.H. Ye: J. Am. Ceram. Soc., 2007, vol. 90, pp. 1521-26.

26. Z.-Y. Deng, Y.-F. Liu, Y. Tanaka, J. Ye, and Y. Sakka: J. Am. Ceram. Soc., 2005, vol. 88, pp. 977-79.

27. A.C.D. Chaklader: U.S. Patent, 2003, 6,582,676 B2.

28. A.N. Streletskii, I.V. Kolbanev, A.B. Borunova, and P.Y. Butyagin: Colloid J., 2005, vol. 67, pp. 631-37. 
29. H.W. Wang, H.W. Chung, H.T. Teng, and G.Z. Cao: Int. J. Hydrog. Energy, 2011, vol. 36, pp. 15136-44.

30. X.-N. Huang, C.-J. Lv, Y. Wang, H.-Y. Shen, D. Chen, and Y.-X. Huang: Int. J. Hydrog. Energy, 2012, vol. 37, pp. 7457-63.

31. A.V. Parmuzina and O.V. Kravchenko: Int. J. Hydrog. Energy, 2008, vol. 33, pp. 3073-76.

32. W. Wang, D.M. Chen, and K. Yang: Int. J. Hydrog. Energy, 2010, vol. 35 , pp. 12011-19.

33. D.O. Flamini, S.B. Saidman, and J.B. Bessone: Corros. Sci., 2006, vol. 48 , pp. 1413-25.

34. O.V. Kravchenko, K.N. Semenenko, B.M. Bulychev, and K.B. Kalmykov: J. Alloy. Compd., 2005, vol. 397, pp. 58-62.

35. X.N. Huang, C.J. Lv, Y.X. Huang, S. Liu, C. Wang, and D. Chen: Int. J. Hydrog. Energy, 2011, vol. 36, pp. 15119-24.

36. K. Mahmoodi and B. Alinejad: Int. J. Hydrog. Energy, 2010, vol. 35 , pp. $5227-32$.

37. E. Van Gheem, J. Vereecken, and C. Le Pen: J. Appl. Electrochem., 2002, vol. 32, pp. 1193-1200.

38. E. McCafferty: Corros. Sci., 2003, vol. 45, pp. 1421-38.

39. L. Takacs: Prog. Mater. Sci., 2002, vol. 47, pp. 355-414.

40. C. Suryanarayana: Prog. Mater. Sci., 2001, vol. 46, pp. 1-184.

41. R.A.Young: in The Rietveld Method, IUCr Monographs on Crystallography, R.A.Young, ed., Oxford University Press, Washington, DC, 1996, pp. 1-38.

42. B.R. Strohmeier: Surf. Interface Anal., 1990, vol. 15, p. 51.

43. J.B. Fogognolo, F. Velasco, M.H. Robert, and J.M. Torralba: Mater. Sci. Eng. A, 2003, vol. 342, pp. 131-43.

44. S.S. Razavi Tousi, R. Yazdani Rad, E. Salahi, I. Mobasherpour, and M. Razavi: Powder. Technol., 2009, vol. 192, pp. 346-51.

45. J.A. Rodriguez, J.M. Gallardo, and E.J. Herrera: J. Mater. Sci., 1997, vol. 32, pp. 3535-39.

46. W.-Z. Gai, Z.-Y. Deng: Int. J. Hydrog. Energy, 2014, doi: 10.1016/j.ijhydene.2014.02.087.

47. M.-Q. Fan, F. Xu, L.-X. Sun, J.-N. Zhao, T. Jiang, and W.-X. Li: J. Alloy. Compd., 2008, vol. 460, pp. 125-29.

48. X. Chen, Z. Zhao, X. Liu, M. Hao, A. Chen, and Z. Tang: $J$. Power Sources, 2014, vol. 254, pp. 345-52.

49. Y. Liu, X. Wang, H. Liu, Z. Dong, S. Li, H. Ge, and M. Yan: Energy, 2014, doi:10.1016/j.energy.2014.05.060.
50. R.K. Hart: Trans. Faraday Soc., 1957, vol. 53, pp. 1020-27.

51. E. Gurses, H. Wafai, and T. El Sayed: Model. Simul. Mater. Sci., 2013, vol. 21, p. 015001.

52. C. Saldana, T.G. Murthy, M.R. Shankar, E.A. Stach, and S. Chandrasekar: Appl. Phys. Lett., 2009, vol. 94, p. 021910.

53. J.A. Haber and W.E. Buhro: J. Am. Chem. Soc., 1998, vol. 120, pp. $10847-55$.

54. K. Zhang, J.R. Weertman, and J.A. Eastman: Appl. Phys. Lett., 2004, vol. 85 , pp. 5197-99.

55. K.D. Ralston and N. Birbilis: Corrosion, 2010, vol. 66, pp. 075005-13

56. D. Song, A.-B. Ma, J.-H. Jiang, P.-H. Lin, and D.-H. Yang: Trans. Nonferrous Met. Soc. China, 2009, vol. 19, pp. $1065-70$.

57. E. Sikora, X.J. Wei, and B.A. Shaw: Corrosion, 2004, vol. 60, pp. 387-98.

58. E. Kus, Z. Lee, S. Nutt, and F. Mansfeld: Corrosion, 2006, vol. 62 , pp. $152-61$

59. M.-K. Chung, Y.-S. Choi, J.-G. Kim, Y.-M. Kim, and J.-C. Lee: Mater. Sci. Eng. A, 2004, vol. 366, pp. 282-91.

60. T.C. Tsai and T.H. Chuang: Mater. Sci. Eng. A, 1997, vol. 225 , pp. $135-44$.

61. T.S. Mahmoud: Proc. Inst. Mech. Eng. C, 2008, vol. 222, pp. 1117-23.

62. W.R. Osório, C.M. Freire, and A. Garcia: Mater. Sci. Eng. A, 2005, vol. 402, pp. 22-32

63. H. Leth-Olsen, J.H. Nordlien, and K. Nisancioglu: Corros. Sci., 1998, vol. 40, pp. 2051-63.

64. K.D. Ralston, N. Birbilis, and C.H.J. Davies: Scripta Mater., 2010, vol. 63, pp. 1201-04.

65. S.I. Pyun and S.M. Moon: J Solid State Electrochem., 2000, vol. 4, pp. $267-72$.

66. W.J. Bernard and J.J. Randall: J. Electrochem. Soc., 1960, vol. 107 , pp. $483-87$.

67. A. Stralin and T. Hjertberg: Appl. Surf. Sci., 1994, vol. 74, pp. $263-75$.

68. R.S. Alwitt: J. Electrochem. Soc., 1974, vol. 121, pp. 1322-28.

69. X. Chen, Z. Zhao, M. Hao, and D. Wang: J. Power Sources, 2013, vol. 222, pp. 188-95. 